\title{
Editorial: The Fall into the Quotidian
}

'Dear Doktor Professor Heidegger, I should like to know what you mean by the expression "the fall into the quotidian." When did this Fall occur? Where were we standing when it happened?' Why is this so terribly funny? And, other than posting Saul Bellow's Herzog a copy of Being and Time, is a reply from Doktor Professor Heidegger imaginable?

Herzog's letter to Heidegger, and also to Herr Nietzsche (on the 'luxury of Destruction') and to Spinoza ('It may interest you to know that in the twentieth century random association is believed to yield up the deepest secrets of the psyche') may cause philosophers from the English speaking world a momentary sense of superiority over their European counterparts. But they should pause.

'Dear Professor Quine, You say that to be is to be the value of a variable. I wonder if you could kindly tell me how much the average variable is worth?' 'Dear Sir Karl, I read in The Logic of Scientific Discovery that the statement "Here is a glass of water" cannot be verified by any observational experience. Does this mean that the water I have just drunk might actually have been vodka?' 'Dear Professor Dennett, Since seeing The Living Dead I have been worried that I might be a zombie myself, but reading your book, I see that there is no one here to do any worrying: but the worries won't go away. Please sort me out.' 'Dear Professor Goodman, Its nearly 2,000, and I'm very concerned about what might happen to Madeleine's emeralds.'

Readers will be able to write their own Herzogographs to the philosophical authorities of our day. Beneath the amusement, what this shows is that, like painting, philosophy is a subject with a long history, and that it never approaches the external world directly. As painting it always does so through its existing traditions and problems. Unlike Das Man, philosophy does not fall straight into the quotidian. 